\title{
Ornithine decarboxylase activity is a marker of premalignancy in longstanding Helicobacter pylori infection
}

\author{
S E Patchett, P H Katelaris, Z W Zhang, E M Alstead, P Domizio, M J G Farthing
}

\begin{abstract}
Background-Longstanding Helicobacter pylori infection may increase the risk of developing gastric adenocarcinoma. The sequence of chronic active gastritis leading to gastritis with atrophy and subsequent intestinal metaplasia is thought to be a key step in gastric carcinogenesis. Ornithine decarboxylase (ODC) activity is increased in some pre-malignant gastrointestinal conditions and is essential for malignant transformation in vitro.

Aims-To measure ODC activity in the antrum of $H$ pylori infected and noninfected subjects and to relate this to histological abnormalities associated with recent and longstanding $H$ pylori infection.

Methods-Six antral mucosal biopsy specimens were obtained from 75 patients for detailed histological assessment and measurement of ODC activity. Samples were measured in duplicate and results expressed as median, interquartile range in $\mathbf{~ p m o l} / \mathrm{mg}$ protein/h.
\end{abstract}

Results-ODC activity was significantly higher in $H$ pylori positive $(164,88-259$ pmol/mg/h) than $H$ pylori negative subjects $(99 \cdot 8,55-158 \mathrm{pmol} / \mathrm{mg} / \mathrm{h}, p=0 \cdot 003)$. However the presence of gastritis, irrespective of the severity of inflammation or activity had no influence on ODC activity. Gastritis with atrophy was associated with increased ODC activity, which was closely related to the severity of the atrophy $(p=0.01)$. Similarly, ODC activity was significantly increased in subjects with intestinal metaplasia (196, 83-25) compared with those without intestinal metaplasia $(111 \cdot 7,65-175, \mathrm{p}<0 \cdot 04)$.

Conclusions-These results indicate that the histological changes associated with longstanding $H$ pylori infection rather than inflammation alone are associated with increased polyamine biosynthetic activity. This may be relevant to $H$ pylori associated gastric carcinogenesis.

(Gut 1996; 39: 807-810)

Keywords: ornithine decarboxylase, Helicobacter pylori, intestinal metaplasia, gastric atrophy.

Although the rates of gastric cancer have been declining in recent years, it remains the fourth most common cause of cancer death in the United Kingdom, accounting for almost 10000 deaths each year. ${ }^{1}$ The reasons for the decline in gastric malignancy are unclear but is probably because of a reduction in distal gastric cancers of the intestinal type. ${ }^{2}$ This is in contrast with tumours of the proximal stomach, which seem to be increasing in frequency in developed countries. ${ }^{3}$

Helicobacter pylori causes chronic active gastritis and its presence is strongly associated with peptic ulcer disease. ${ }^{45}$ More recently, several studies strongly support its role as an aetiological factor in the development of gastric cancer. ${ }^{6}{ }^{7} \mathrm{H}$ pylori is a chronic infection that typically remains active for life. It is thus a probable source of active inflammation lasting for decades, which is thought to progress to atrophy with time. This is in accordance with Correa's hypothesis of gastric carcinogenesis in which gastric mucosa progresses from chronic gastritis through atrophy to metaplasia, dysplasia, and finally cancer. ${ }^{8}$

Ornithine decarboxylase (ODC) is the first and rate limiting step in the biosynthesis of polyamines, which are ubiquitous intracellular bases required for normal and neoplastic growth. ${ }^{9}$ This enzyme has been implicated as an essential promoter of cellular proliferation and tumour development. ${ }^{10}{ }^{11}$ In this study, we have measured ODC activity in gastric mucosa of subjects with $H$ pylori infection and have related this to the presence and severity of inflammatory and putative premalignant mucosal changes known to be associated with longstanding $H$ pylori infection.

\section{Methods}

\section{Patients}

Patients with dyspepsia attending for upper gastrointestinal endoscopy were recruited for the study. Patients taking non-steroidal antiinflammatory agents, antibiotics, bismuth preparations, or proton pump inhibitors within a month of endoscopy were excluded from the study as were patients who had undergone previous gastric resection.

\section{Study design}

Using standard endoscopy forceps, six gastric mucosal biopsy specimens were obtained from within $2 \mathrm{~cm}$ of the pylorus. Three specimens were obtained for measurement of ODC activity and three were used for histological assessment of antral mucosa.

Specimens were fixed in formal saline, processed routinely, and embedded in paraffin wax. Four $\mu \mathrm{m}$ sections were cut from each 
Relation between histological findings and $O D C$ activity in gastric antral mucosa

\begin{tabular}{llll}
\hline Histology & Number (\%) & $\begin{array}{l}\text { Median ODC activity } \\
(\text { pmolmg/h) }\end{array}$ & IQR \\
\hline Normal & $23(30 \cdot 6)$ & 106 & $32-164$ \\
Chronic active gastritis only & $18(24 \cdot 0)$ & 82 & $30-155$ \\
Gastritis with atrophy (no IM) & $19(25 \cdot 3)$ & 156 & $34-250$ \\
Intestinal metaplasia & $15(20 \cdot 1)$ & 196 & $38-259$ \\
\hline
\end{tabular}

$\mathrm{p}<0.003$ (Kruskall-Wallis).

specimen and stained using haematoxylin and eosin, a combined alcian blue/periodic acidSchiff stain and a modified Giemsa method. The degree of histological change in the gastric antral biopsy specimens was classified in accordance with the Sydney system. ${ }^{12}$ The severity (mononuclear cell infiltrate) and activity (polymorph infiltrate) of inflammation, glandular atrophy, and intestinal metaplasia was graded by a single pathologist (PD) for each variable on a 4 point scale from 0 (absent) to 3 (severe).

Mucosal ODC activity was assayed using a modification of the method described by Beaven et al. ${ }^{13}$ After collection, samples were immediately snap frozen in liquid nitrogen and stored at $-70^{\circ} \mathrm{C}$ before analysis. Samples were subsequently homogenised using an UltraTurrac homogeniser in $300 \mu l$ of buffer containing $0.1 \mathrm{M}$ TRIS ( $\mathrm{pH} 7 \cdot 2$ ), $5 \mathrm{mM}$ dithiothreitol (DTT), and $0.25 \mathrm{mM}$ pyridoxal phosphate. The reaction mixture consisted of $15 \mu$ l of homogenate, $0.25 \mathrm{mM}$ pyridoxal phosphate, $5 \mathrm{mM}$ DTT with $0.15 \mu \mathrm{Ci}$ of $\mathrm{L}-\left[{ }^{14} \mathrm{C}\right]$-ornithine hydrochloride (Amersham International) in a total volume of $30 \mu \mathrm{l}$. The reaction tube was sealed with a rubber cap in which was embedded a $0.5 \mathrm{~cm}$ square of Whatman No 1 filter paper soaked with $50 \mu \mathrm{l}$ methylbenzethonium hydroxide. Tubes were incubated at $37^{\circ} \mathrm{C}$ for 60 minutes and the reaction then stopped by injecting $100 \mu l 20 \%$ trichloroacetic acid. After an additional 30 minutes incubation for equilibration, the filter paper was removed and placed into $5 \mathrm{ml}$ of scintillation fluid and counted in LKB Wallac Ultra-beta 1210 scintillation counter. The protein content of the homogenate was estimated using the bicinchoninic acid microtitre protein
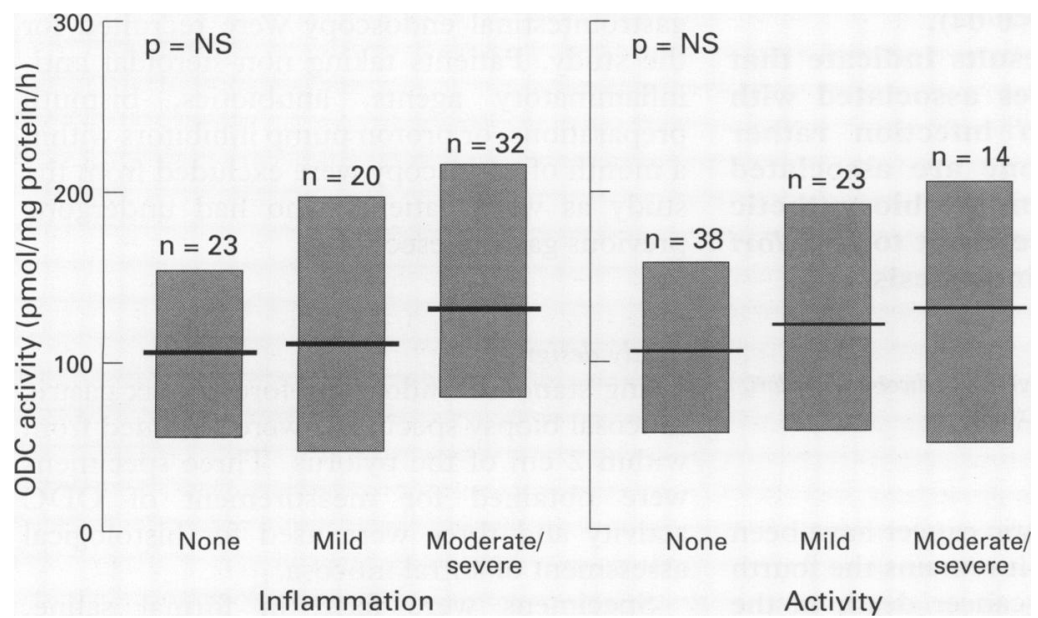

Figure 1: ODC activity related to severity of inflammation and activity of gastritis (median (interquartile range)). assay (Pierce). Samples were measured in duplicate and expressed in $\mathrm{pmol} / \mathrm{mg}$ protein $/ \mathrm{h}$.

\section{Statistical analyses}

Data are presented as group medians with interquartile ranges. Differences in ODC activity between histological groups were analysed using the Kruskal-Wallis test and differences between pairs were analysed using the Wilcoxon test for unpaired data. Data regarding ODC activity and severity of gastritis and atrophy were analysed using a non-parametric test for trend (Cuzick's test). ${ }^{14}$ Values of less than 0.05 were considered significant in all analyses.

\section{Results}

ODC activity, $H$ pylori status, and antral histology was assessed in 75 patients ( 45 male) with a mean age of 54.8 years (range 18-82). Thirty five patients $(46.6 \%)$ were $H$ pylori positive. Median ODC activity was significantly higher in patients with $H$ pylori infection (164, 88-259) compared with those who were $H$ pylori negative $(99 \cdot 8,55-158), \mathrm{p}<0.003)$. The Table shows antral histological findings in all 75 patients and median ODC activity for each group. ODC activity in patients with chronic active gastritis alone was not significantly different from those with normal antral histology. Indeed in the group as a whole, neither the severity of gastritis or activity of gastritis was significantly related to the level of ODC activity suggesting that the degree of antral gastritis in itself was not a determinant of ODC activity (Fig 1). More advanced antral histological changes were however associated with increased polyamine biosynthetic activity. Figure 2 shows the relation between the presence and severity of gastric atrophy. A statistically significant stepwise increase in median ODC activity is evident as the presence and degree of atrophy increases $(p<0.001)$. Furthermore, patients with severe atrophy had significantly higher ODC activity than either those with mild atrophy or those without atrophy $(\mathrm{p}<0.01)$. Of the 75 patients studied, $15(20 \%)$ were found to have evidence of intestinal metaplasia. The median ODC

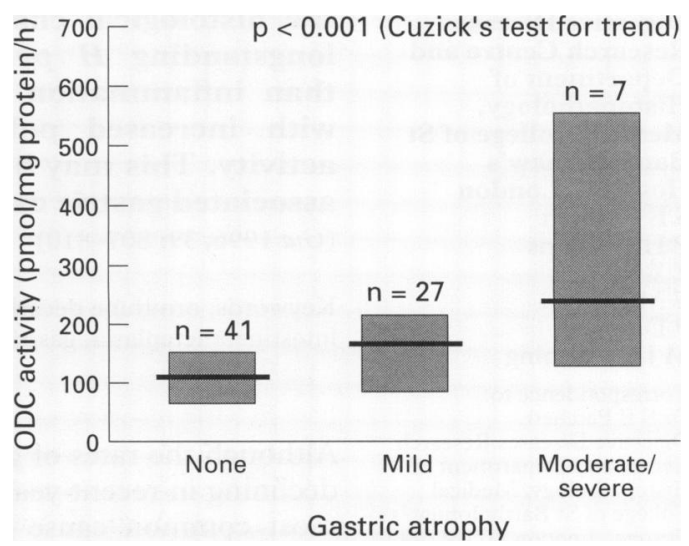

Figure 2: $O D C$ activity related to presence and severity of atrophy (median (interquartile range)). 


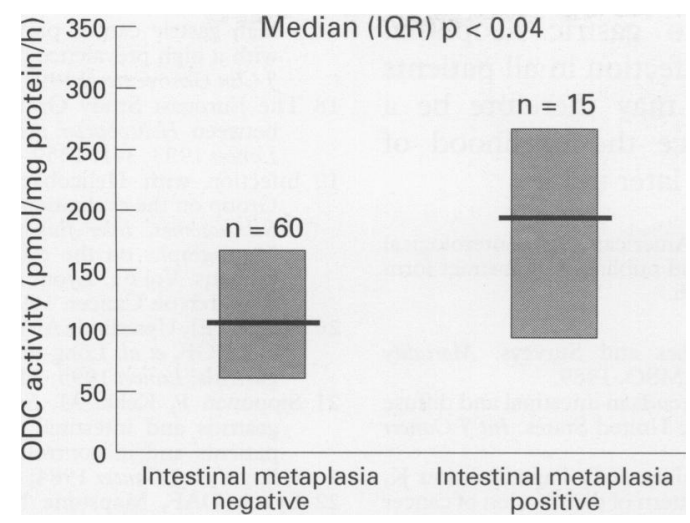

Figure 3: $O D C$ activity in patients with and without intestinal metaplasia (median (interquartile range)).

activity in this group of patients was significantly higher than in those without intestinal metaplasia $(\mathrm{p}<0.04)$ (Fig 3).

\section{Discussion}

$H$ pylori infection is the cause of chronic active gastritis and is a major factor in the aetiopathogenesis of peptic ulcer disease. ${ }^{45}$ There is now substantial evidence to support a link between chronic $H$ pylori infection and subsequent development of gastric cancer. ${ }^{715}$ $H$ pylori infection is more common in patients with gastric carcinoma, than in healthy controls ${ }^{16}$ and gastric cancer is many times more prevalent in populations with very high rates of $H$ pylori infection. ${ }^{17}{ }^{18}$ Accordingly a WHO working group have recently concluded that sufficient evidence exists to support a causal role between $H$ pylori and gastric cancer. ${ }^{19}$ Gastric carcinogenesis is however a multi-step process progressing through the stages of gastritis, atrophy, metaplasia, and dysplasia. ${ }^{8}$ Recent studies have also confirmed that longterm infection with $H$ pylori is a significant risk factor for the development of atrophy and intestinal metaplasia in the stomach. ${ }^{2021}$

Several studies have shown that diseases predisposing to gastrointestinal cancer are associated with modifications of epithelial cell proliferation and differentiation. In the human stomach, expansion of the proliferative compartment of epithelial cells and a true hyperproliferative state is associated with histological abnormalities associated with gastric cancer. Several groups have now shown that infection with $H$ pylori is associated with an increase in mucosal proliferation assessed immunohistochemically, and that this increase in mucosal proliferation can be reversed through eradication of the organism. ${ }^{22-25}$ Other studies have reported increased mucosal proliferation in gastric atrophy but not in superficial gastritis. ${ }^{26}$ Increased cell turnover associated with chronic $H$ pylori infection is thought to be the first pre-morphological change in the pathway leading to frank cancer formation.

ODC activity is considered to be a biochemical marker of cell turnover and plays a key part in the onset of cell proliferation. ODC is expressed at low activity in quiescent cells but activity rapidly increases when cells enter a proliferative phase. ${ }^{27}$ Chemical promoters of malignancy increase ODC activity in rats ${ }^{28}$ and cancer cells invariably contain high concentrations of polyamines probably as a manifestation of this increased proliferative rate. This central role of ODC in the carcinogenic process has suggested that it might be of value as a screening tool for those at risk of developing pre-cancer or cancer. In patients with familial adenomatous polyposis (FAP) for example, ODC activity is relatively low in morphologically normal mucosa but increases with the development of adenomas and with dysplasia. ${ }^{29}$ Furthermore, phenotypically normal relatives of FAP patients who possess the FAP genotype have increased colonic ODC activity, which precedes the development of morphological changes. ${ }^{29}$

Increased ODC activity has also been reported in the morphologically normal mucosa of patients with sporadic colorectal adenomas ${ }^{30}$ and in dysplastic Barrett's oesophageal mucosa $^{31}$ and in the postoperative stomach. ${ }^{32}$ Moreover, in vitro studies suggest that polyamine synthesis is required for malignant transformation of epithelial cell lines. ${ }^{33}$ In this study, we have examined the relation between polyamine biosynthetic activity and the associated antral histological change that results from $H$ pylori infection. The results indicate that longterm $H$ pylori infection is associated with an increase in ODC activity when compared with uninfected patients. Our findings are in accord with previous immunohistochemical studies relating $H$ pylori infection to changes in mucosal proliferation. ${ }^{22-24}$ The presence of inflammation in itself however, was not an important determinant of ODC activity as the severity of activity or inflammation was not significantly related to levels of ODC activity. The presence of atrophy and intestinal metaplasia was strongly associated with increased levels of ODC activity, with more severe atrophy being associated with higher ODC levels. These data are entirely consistent with the views of Kuipers and others who have suggested that atrophy and metaplasia are the result of longterm $H$ pylori infection, which then predispose to the development of gastric cancer. $^{2021}$ That the highest levels of ODC activity are associated with atrophy and intestinal metaplasia, suggests that it is the consequence of $H$ pylori infection, rather than the presence of the organism itself, which is responsible for increased polyamine biosynthesis. Although we have not examined the effect of $H$ pylori eradication on ODC activity, immunohistochemical data suggest that eradication of the organism is associated with a decrease in mucosal proliferation. ${ }^{22}{ }^{24}$ There is no convincing evidence however that established atrophy or metaplasia can be reversed by treatment, though chronic inflammation is readily cured with eradication treatment.

Our findings indicate therefore that increased polyamine biosynthetic activity is increased in antral lesions associated with longterm $H$ pylori infection and support the concept that these histological changes are associated 
with a predisposition to gastric neoplasia. Eradication of $H$ pylori infection in all patients regardless of symptoms may therefore be a reasonable aim to reduce the likelihood of developing gastric cancer later in life.

This work was presented at the American Gatroenterological Association, New Orleans 1994 and published in abstract form in Gastroenterology 1994; 106: A426.

1 Office of Population Censuses and Surveys. Mortality statistics by cause. London: HMSO, 1989.

2 Munoz N, Connelly R. Time trends in intestinal and diffuse types of gastric cancer in the United States. Int 7 Cancer types of gastric ca
$1971 ; 81: 58-64$.

3 Golematis B, Tzardis P, Hatzikostas P, Papadimitriou K, Haritpoulos $N$. Changing pattern of distribution of cancer of the stomach. Br $\mathcal{F}$ Surg 1990; 77: 63-4.

4 Rauws E, Langenberg W, Houthoff $H$, Zanen H, Tytgat G. Campylobacter pyloridis associated chronic active antral gastritis. Gastroenterology 1988; 94: 33-40.

5 Graham DJ. Campylobacter pylori and peptic ulcer disease. Gastroenterology 1989; 96: 615-25.

6 Parsonnet J, Samloff IM, Nelson LM, Orentreich N, Vogelman JH, Friedman GD. Helicobacter pylori, pepsinogen, and risk for gastric adenocarcinoma. Cancer Epidemiol Biomarkers Prev 1993; 2: 461-6.

7 Nomura A, Stemmermann GN, Chyou PH, Kato I, PerezPerez GI, Blaser MJ. Helicobacter Pylori infection and Perez GI, Blaser MJ. Helicobacter Pylori infection and gastric carcinoma among Japanes

8 Correa P. A human model of gastric carcinogenesis. Cancer Res 1995; 48: 3554-60.

9 Heby O. Role of polyamines in the control of cell proliferation and differentiation. Differentiation 1981 ; 19: $1-20$.

10 O'Brien TG. The induction of ornithine decarboxylase as an early, possibly obligatory event in mouse skin carcinogenesis. Cancer Res 1976; 36: 2644-53.

11 Boutwell RK. Evidence that an elevated level of ornithine decarboxylase activity is an essential component of tumour promotion. Adv Polyamine Res 1983; 4: 127-33.

12 Price AB. The Sydney System: Histological division. $f$ Gastroenterol Hepatol 1991; 6: 209-22.

13 Beaven MA, Wilcox G, Terpstra GK. A microprocedure for the measurement of ${ }^{14} \mathrm{CO}_{2}$ release from $\left[{ }^{14} \mathrm{C}\right]$ carboxyllabelled amino acids. Anal Biochem 1987; 84: 638-41

14 Cuzick J. A wilcoxon-type test for trend. Stat Med 1985; 4: 87-90.

15 Parsonnet J, Friedman GD, Vandersteen DP, Chang Y, Vogelman JH, Orentreich $\mathrm{N}$, et al. Helicobacter pylor infection and the risk of gastric carcinoma. $N$ Engl f Med 1991; 325: 1127-31.

16 Hansson LE, Engstrand L, Nyren O, Evans DJ, Lindgren A, Bergstrom $\mathbf{R}$, et al. Helicobacter pylori infection: independent risk indicator of gastric adenocarcinoma. Gastroenterology 1993; 105: 1098-103.

17 Burstein $M$, Monge E, Leon-Barua $R$, Lozano $R$ Berendson R, Gilman RH, et al. Low peptic ulcer and high gastric cancer prevalence in a developing country with a high prevalence of infection by Helicobacter pylori. f Clin Gastroenterol 1991; 13: 154-6.

18 The Eurogast Study Group: An international association between Helicobacter pylori infection and gastric cancer. Lancet 1993; 341: 1359-62.

19 Infection with Helicobacter pylori. In: IARC Working Group on the evaluation of carcinogenic risks to humans. Schistosomes, liver flukes and Helicobacter pylori. IARC Monographs on the evaluation of carcinogenic risks to humans. Vol 61. Lyon, France: International Agency for Research on Cancer, 1994: 177-240.

20 Kuipers EJ, Uyterlinde AM, Pena AS, Roosendaal R, Pals G, Nelis GF, et al. Long-term sequelae of Helicobacter pylori Nelis GF, et al. Long-term sequelae

21 Sipponen P, Kekki M, Siurala M. Age-related trends of gastritis and intestinal metaplasia in gastric carcinoma patients and in controls representing the population at large. $B r f$ Cancer 1984; 49: 521-30.

22 Lynch DAF, Mapstone NP, Clarke AMT, Sobala GM, Jackson P, Morrison L, et al. Cell proliferation in Helicobacter pylori associated gastritis and the effect of eradication therapy. Gut 1995; 36: 346-50.

23 Cahill RJ, Xia H, Kilgallen C, Beattie S, Hamilton H, O'Morain C. Effect of eradication of $\mathrm{H}$ pylori infection on gastric epithelial cell proliferation. Dig Dis Sci 1995; 40: $1627-31$

24 Brenes F, Ruiz B, Correa P, Hunter F, Rhamakrishnan T, Fontham E, et al. Helicobacter pylori causes hyperproliferation of the gastric epithelium: pre and post proliferation of the gastric epithelium: pre and post Am $₹$ Gastroenterol 1993; 88: 1870-5.

25 Fraser AG, Sim R, Sankey EA, Dhillon AP, Pounder RE. Effect of eradication of $\mathrm{H}$ pylori infection on gastric epithelial cell proliferation. Aliment Pharmacol Therap 1994; 8: 167-73.

26 Hansen OH, Johansen AA, Larsen JK, Svendson LB. Cell proliferation in normal and diseased gastric mucosa. Acta Pathol Microbiol Scand 1979; 87: 217-22.

27 Luk G, Baylin SB. Polyamines and intestinal growth increased polyamine biosynthesis after jejunectomy. $\mathrm{Am}$ f Physiol 1983; 245: G656-60.

28 Rozhin J, Wilson PS, Bull AW, Nigro ND. Ornithine decarboxylase in the rat and human colon. Cancer Res 1984; 44: 3226-30.

29 Luk GD, Baylin SB. Ornithine decarboxylase as a biological marker in familial colonic neoplasia. $N$ Engl f Med 1984; marker in $80-3$.

30 NarishawaT, TakahashiM,Niwa M, Koyama H, KotanagiH, Kusaka $\mathrm{N}$. Increased mucosal ornithine decarboxylase activity in large bowel with multiple tumours, adenocarcinoma, and adenoma. Cancer 1989; 63: 1572-6.

31 Garewell HS, Sampliner R, Alberts D, Steinbronn K. Increase in ornithine decarboxylase activity associated with the development of dysplasia in Barrett's oesophagus. Dig Dis Sci 1989; 34: 312-4.

32 Patchett SE, Alstead EM, Butruk L, Przytulski K, Farthing MJG. Ornithine decarboxylase as a marker for premalignancy in the stomach. Gut 1995; 37: 13-6.

33 Auvinen M, Paasinen A, Anderson LC, Holtta E. Ornithine decarboxylase activity is critical for cell transformation. Nature 1992; 360: 355-8. 